\title{
Access to Healthy Food Stores for Residents of Aboriginal Reserves in Rural British Columbia
}

\author{
Amirmohsen Behjat ${ }^{1}$, Aleck Ostry ${ }^{2}$, Christina Miewald ${ }^{2,3}$ and Bernie Pauly ${ }^{4}$ \\ 1. College of Science and Humanities, Husson University, Bangor 04401, Maine, United States \\ 2. Department of Geography, University of Victoria, Victoria, BC, V8P5C2, Canada \\ 3. Department of Geography, Simon Fraser University, Burnaby, BC, V5A1S6, Canada \\ 4. School of Nursing, University of Victoria, Victoria, BC, V8P5C2, Canada
}

\begin{abstract}
The rate of food insecurity has increased tremendously over the past decade in Canada. This increase has been more pronounced in rural and remote areas especially among Aboriginal peoples. Substantial studies indicated that nearly half of the on-reserve Aboriginal households in British Columbia (BC) suffer from some degree of food insecurity. Despite the valuable research about obtaining traditional food, the issue of access to market food has been less discussed in the literature. The aim of this study was to assess the local food environment of on-reserve Aboriginal peoples by using a proximity-based approach tool in terms of access to healthy food stores such as supermarket and grocery stores. In the first stage, the addresses of all healthy food stores were geocoded into a map layer. Then the locations of Aboriginal reserves were geocoded to a separate map layer. In the second stage, using "Closest Facility Analysis” tool in ArcGIS Version 10.3, the distance based on a 15-minute driving time was measured from each reserve to the closest healthy food destination on CanMapRouteLogistics network. The results indicated that $25 \%$ of Aboriginal reserves did not have reasonable access to healthy food stores. We concluded that Aboriginal peoples in low access rural reserves with lower socioeconomic status are at potential risk of perpetuate food insecurity.
\end{abstract}

Key words: Food security, rural aboriginal reserves, network analysis, ArcGIS.

\section{Introduction}

It is well- proven that food insecurity is one of the most serious and problematic issues among Aboriginal peoples in Canada [1-3]. Regardless of living in urban or rural areas, Tarasuk et al. [4] indicated that, off-reserve Aboriginal households had a rate of food insecurity more than twice that of the average Canadian household. They asserted that this rate (27\%) is an underestimation and cannot be generalized to all Aboriginal households as Statistics Canada did not utilize on-reserve Aboriginal household data in the 2011 Canadian Community Household Survey (CCHS). In British Columbia (BC), Canada, the rate of food insecurity among off-reserve Aboriginal communities is around three times the average people [5]. In terms of on-reserve Aboriginal peoples, Chan et

Corresponding author: Amirmohsen Behjat, assistant professor, research fields: food security and public health. al. [6] conducted a comprehensive study and reported that $45 \%$ of the on-reserve Aboriginal households in BC suffer from some degree of food insecurity.

Substantial research has indicated the strong association between food insecurity with chronic diseases such obesity, diabetes, and hypertension [7-10]. For example, The Public Health Agency of Canada [11] reported that the obesity prevalence among BC Aboriginal peoples is relatively higher than their counterparts in other parts of Canada. Similarly, Foulds et al. [12] conducted a research on 759 Aboriginal adults (both on and off reserves) to investigate their weight status in BC. The results indicated that around $78 \%$ of the Aboriginal participants were either overweight or obese. According to Government of Canada [13], the age-standardized prevalence of diagnosed diabetes among Aboriginal peoples in British Columbia was 
6.7\%, compared with $4.8 \%$ among non-Aboriginal British Columbians. Harris et al. [14] pointed out that the mortality rate of Aboriginal peoples with diabetes is about twice their Aboriginal counterparts without diabetes.

Aboriginal peoples' diet consists of both traditional and market foods [15, 16]. The composition of traditional and market foods varies across Aboriginal communities. The Council of Canadian Academies [17] discussed that the dietary intake of Aboriginal peoples has shifted towards market food in the past decade. They added that dependency to market foods is around $70 \%$ in some Aboriginal communities. One of the main reasons of this tendency is lack of access to traditional foods which is based on food sharing network and social capital [18]. Due to the high cost of hunting in terms of equipment and gas, and the rapid depletion of traditional food resources to the negative impact on ecosystems and food chains from climate change, food sharing networks have decreased in some Aboriginal communities in recent years [19-21].

Market foods include both healthy and unhealthy foods. Healthy foods are more frequent in grocery stores and supermarkets whereas unhealthy foods are more available in convenience stores, gas stations, and general stores [22, 23]. While access to traditional foods has become more challenging to Aboriginal peoples in recent years, there will be no alternative but to rely on healthy food stores to practice a relatively healthy diet. However, lack of access to healthy food stores can exacerbate the food insecurity of Aboriginal peoples. According to a study of remote First Nations reserves in rural Northwestern Ontario conducted by Gittelsohn and Sharma [24], most reserves have no healthy food stores within their communities for regular shopping, which compels residents to drive for up to two hours to procure basic food items. Willows [25] pointed out that aboriginal communities in rural and remote areas suffer from a lack of access to healthy food items, especially fruit and vegetables in
Canada. Thompson et al. [26] mentioned that Aboriginal people in rural and remote areas have inadequate access to food stores, and this problem is compounded by poor road networks in their communities. Moreover, Chan et al. [6] explained that lack of transportation is a major barrier for on-reserve Aboriginal people in obtaining traditional foods in BC.

While majority of studies have investigated the issue of food insecurity through the traditional food systems in Aboriginal communities [27-29], access to healthy food stores has been less discussed across the literature. The main goal of this study is to evaluate the geographic access of Aboriginal peoples in rural reserve to healthy food stores in BC. Moreover, we compared the geographic access to healthy food stores for Aboriginal people living on BC's rural reserves with average rural residents who are not living on reserves.

\section{Data and Methods}

\subsection{Defining Healthy Food Stores}

As the food business is highly dynamic, we sought to obtain the most recent and updated data on supermarkets and grocery stores for the year 2015 in rural BC. Moreover, suggested to combine at least two secondary databases to increase the accuracy of food store data, especially for supermarkets and grocery stores [30-32]. Thus, in the first step, the most resent two secondary databases (for year 2015) from InfoCanada Group and Enhanced Point of Estimate (EPOI) (by DMTI Spatial Inc.) [33] were considered for this study. The first commercial database was purchased from InfoCanada Group and the second database, EPOI, was obtained through British Columbia Research Libraries' Data Service. Then, in addition to the two commercial databases, food store data were also collected from online directory (BC Yellow Pages) source. After cross-checking the three (two commercial and one internet-derived) databases and eliminating the duplications, an improved food 
store database was used to characterize the food environment in this study.

In order to differentiate healthy food stores (grocery stores and supermarkets) from other food stores in rural food environment, we used North American Industry Classification System (NAICS) codes in this study. The NAICS code 445110 which is commonly used to exclude food outlets which offer very limited food options such as convenience stores and restaurants from those classified as healthy food stores [34]. Thus, food stores were filtered based on NAICS code 445110 to obtain the list of supermarkets and grocery stores in this study. It should be noted that majority of rural farmers' markets (76\%) are seasonal and the permanent rural farmers' markets (24\%) which also have very limited operation hours are clustered in Southeast BC. Therefore, farmers' markets were not included in this study.

\subsection{Measuring Geographic Access}

In the first step, using ArcGIS Version 10.3 [35], the addresses of all obtained healthy food stores were geocoded into a map layer. In the second step, data identifying on-reserve Aboriginal communities in rural areas were obtained from British Columbia Aboriginal Network on Disability Society [36] and their locations were geocoded to a separate map layer in ArcGIS. Metro Influence Zone (MIZ) which is a rural-urban continuum code at Dissemination Area (DA) level by Statistics Canada [37] was chosen to make distinction between rural and urban reserves. According to Statistics Canada [37] rural areas are assigned to one of four categories according to the degree of influence (Strong, Moderate, Weak or No influence) that metropolitan areas have on them. Finally, using "Closest Facility Analysis" tool in ArcGIS Version 10.3, the food access based on driving time was measured from each rural reserve to the closest healthy food store on CanMap RouteLogistics [38] network dataset. The reserves which are located more than 15 min driving time, were identified as low-access rural reserves communities. It should be noted that there is a general consensus across the literature that travel time to the closest healthy food stores by any means of transportation (driving, walking, and public transit) up to $15 \mathrm{~min}$ is defined as reasonable access [39]. There is a presumption that driving is the main means of transportation in rural areas to reach the closest point of interest. Moreover, we performed a Mann-Whitney U test using SPSS Version 22.0 [40] to compare the overall food access between Aboriginal rural reserves and non-reserve rural communities in BC. Population Weighted Centroid of each rural DA without rural reserve was chosen to calculate the driving time for non-reserve rural communities to their closest healthy food store in this study.

\section{Results}

There are 170 reserves in BC of which 117 (69\%) are distributed over 97 rural DAs. The distribution of reserves across MIZ rural categories was reported in Table 1.

According to Table 1, more than half of the rural reserves (60) are located in weak MIZ. On the other hand, only 10 (8.6\%) of rural reserves fall into strong MIZ category. In order to measure the food access, in the first step the addresses of all rural reserves were geocoded into BC map with respect to MIZ categories. The results are projected in Fig. 1.

Then, using Network Analyst extension, "Closest Facility Analysis" tool, the distance based on driving time in minutes from rural reserves location to the closest healthy food store was calculated on BC road networks. Restrictions such as speed limits, one-way streets and elevations were incorporated for measuring the driving time to generate the results which represent the real-life driving conditions. The descriptive results of food access measurements based on driving time for rural reserves with respect to MIZs are shown in Table 2. As the food access measurement data for all the population groups (MIZs) are not normally 
Table 1 The distribution of rural aboriginal reserves in BC with respect to MIZs.

\begin{tabular}{llllll}
\hline & \multicolumn{5}{c}{ Rural (MIZs) } \\
\cline { 2 - 6 } & Strong & Moderate & Weak & No & \\
\hline Aboriginal reserves & $10(8.6)$ & $30(25.6)$ & $60(51.3)$ & $17(14.5)$ & $117(100)$ \\
\hline
\end{tabular}

Figures in parentheses indicate percentages.

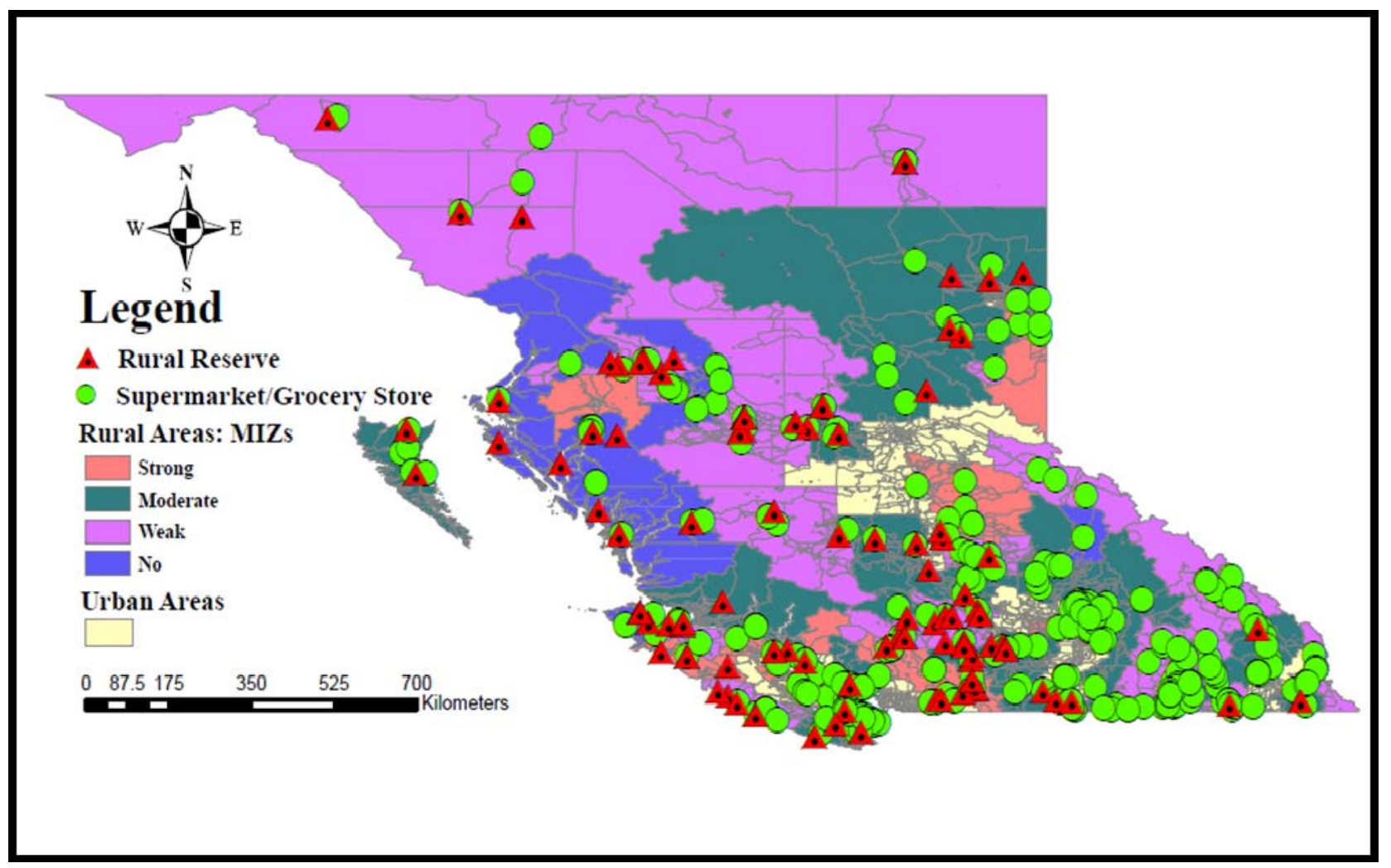

Fig. 1 The distribution of Aboriginal rural reserves across MIZ categories.

Table 2 Descriptive statistics of food access (driving time/minute) for rural reserves across MIZs.

\begin{tabular}{lllll}
\hline Statistics & \multicolumn{3}{c}{ MIZs } \\
\cline { 2 - 5 } & Strong & Moderate & Weak & No \\
\hline $\mathrm{N}$ & 10 & 30 & 60 & 17 \\
Min & 0.6 & 0.1 & 0.1 & 0.1 \\
Max & 33.6 & 62.3 & 90.4 & 26.4 \\
Median & 3.6 & 4.6 & 2.3 & 4 \\
IQR & 11.4 & 9.3 & 23 & 8 \\
\hline
\end{tabular}

distributed ( $p<0.001)$, median and Inter Quartile Range (IQR) are reported instead of mean and standard deviation to investigate the central tendency and variation respectively.

According to Table 2, reserves (e.g., Ahousaht Telegraph Creek, Hartley Bay, and Haisla) with easy access to supermarkets or grocery stores are found in all MIZ categories (driving time $<1 \mathrm{~min}$ ). On the other hand, the maximum driving time (90.4 min) is associated with Squirrel Cove reserve in Weak MIZ. Moreover, Weak MIZ has the greatest variation in driving time for reserve residents to reach supermarkets or grocery stores (IQR $=23 \mathrm{~min}$ ). Surprisingly, reserves in No MIZ regions were found to have the least variation in accessing to healthy food stores (IQR = $8 \mathrm{~min})$. 


\subsection{Low Access Aboriginal Reserves}

A 15 min cut-off was set for identifying the low access rural reserves in $\mathrm{BC}$. The results are projected in Fig 2. It should be noted as socioeconomic data for all the Aboriginal reserves are not available, using my definition, food desert identification cannot be performed for reserves in BC.

Twenty-nine of 117 rural reserves (24.8\%) in BC were classified as low access in terms of driving time to health food stores. The distribution of low access reserves across MIZ categories in rural BC is shown in Table 3.

As indicated in Table 3, Strong and No MIZs have the lowest incidents of low access reserves (two for each category) in rural BC. Surprisingly, only $7.2 \%$ of the low access reserves are found in No MIZ. In contrast, 19 (65\%) of the total low access reserves fell into Weak category. To put it simply, residents of reserves in Weak MIZ have to spend more time and money obtaining healthy food from supermarkets and grocery stores in rural BC.

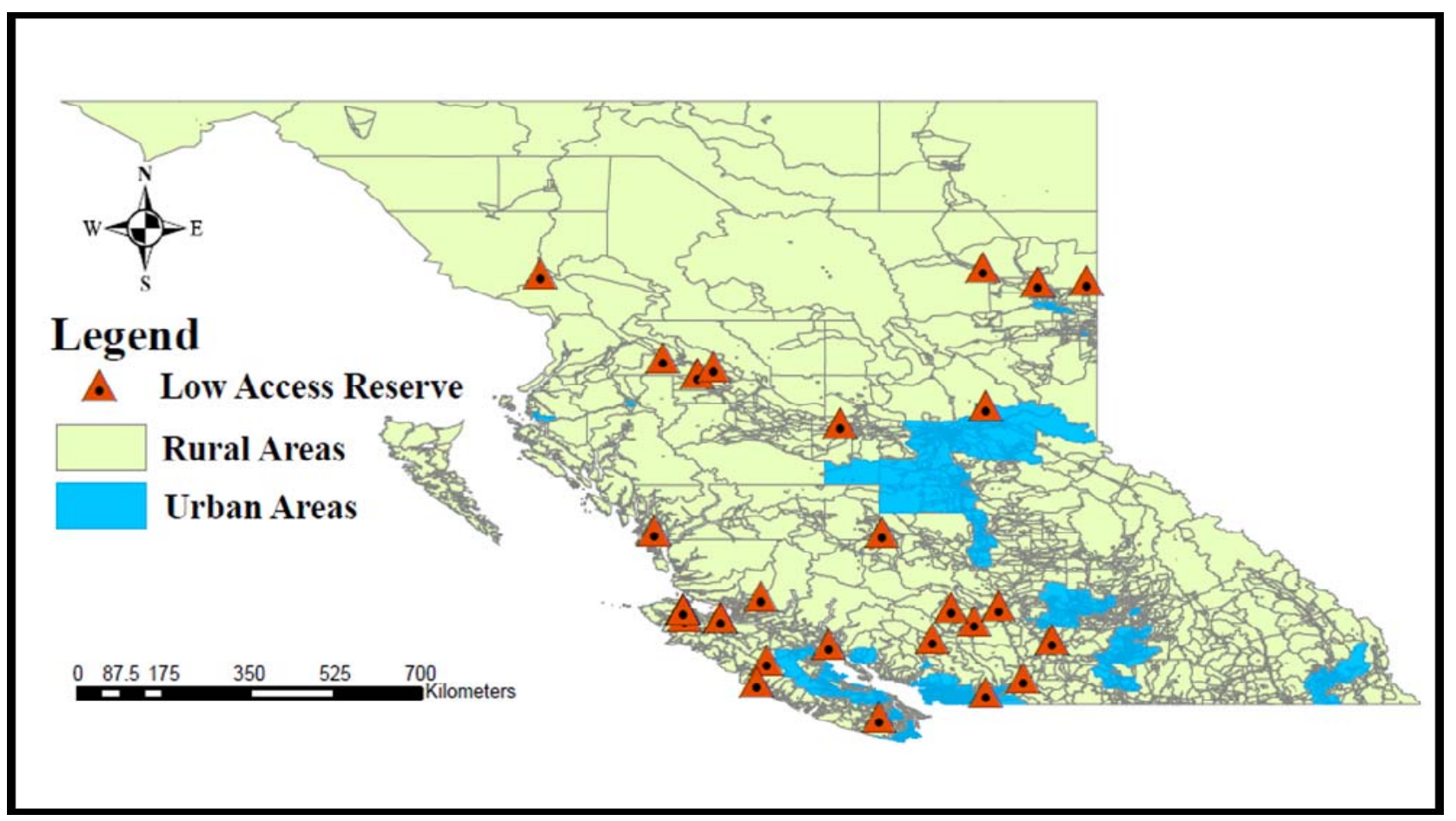

Fig. 2 The distribution of low access rural reserves in BC (driving time $>15 \mathrm{~min}$ ).

Table 3 The distribution of low access reserves across MIZ categories.

\begin{tabular}{llllll}
\hline & \multicolumn{5}{c}{ Rural (MIZs) } \\
\cline { 2 - 6 } & Strong & Moderate & Weak & No & \\
\hline Low access reserves & $2(7.2)$ & $6(20.1)$ & $19(65.5)$ & $2(7.2)$ & 29 \\
\hline
\end{tabular}

Figures in parentheses indicate percentages.

Table 4 Food access level for reserve and non-reserves rural communities in BC.

\begin{tabular}{lllll}
\hline \multirow{2}{*}{ Rural community } & \multicolumn{4}{c}{ Level of access } \\
\cline { 2 - 5 } & $\begin{array}{l}\text { High } \\
(<15 \mathrm{~min})\end{array}$ & $\begin{array}{l}\text { Low } \\
(15-30 \mathrm{~min})\end{array}$ & $\begin{array}{l}\text { Very low } \\
(>30 \mathrm{~min})\end{array}$ & Total \\
\hline Reserves & $88(75.2)$ & $15(12.8)$ & $14(12)$ & 117 \\
Non-reserves (DAs) & $795(73.6)$ & $70(6.5)$ & $215(19.9)$ & 1,080 \\
\hline
\end{tabular}

Figures in parentheses for reserve and non-reserve communities indicate percentages. 
3.2 Comparing Food Access of Reserve and Non-reserve Residents

In this section, we sought to compare the level food access (based on travel time to healthy food stores) between residents of reserves and non-reserves areas (rural DAs without reserves). In the first step, Apparicio et al. [41] and Kaufman's [39] time-based food access categories which are commonly used in food desert studies, were adopted and modified for rural BC. Then the levels of access (high $(<15 \mathrm{~min})$, low (15-30 min), and very low (> $30 \mathrm{~min})$ ) for both reserve and non-reserve British Columbians were calculated. The results are summarized in Table 4.

As shown in Table 4, the percentage of high access category is almost equal for reserve and non-reserve communities. The percentage of low access category is around twice for reserves whilst non-reserve communities are more likely to fall in very low access category. Moreover, an overall food access comparison based on driving time (in minutes) was performed between 117 reserves (distributed over 97 rural DAs) and PWCs of 1,080 non-reserve DAs in this section. Thus, a nonparametric Mann-Whitney U-Test was conducted with the null hypothesis that there is no difference between the median food access of reserve and non-reserve communities. According to the results (Mann Whitney $\mathrm{U}, \mathrm{Z}=-0.438, \mathrm{P}=0.662$ ), the null hypothesis cannot be rejected in favor of alternate hypothesis. In other words, residents of reserve and non-reserves communities in rural BC have equal geographic access (based on driving time) to healthy stores.

\section{Discussion}

This study attempted to determine geographic access to healthy food stores for residents of rural reserves in $\mathrm{BC}$. The results indicated that twenty nine of 117 rural reserves (24.8\%) in BC were classified as low access in terms of driving time to healthy food stores. In other words, the residents of low access reserves must drive more than 15 min to reach the closest supermarket or grocery store. The driving time is more than an hour for residents of Squirrel Cove (in Strathcona regional district), Doig River (in Peace River regional district), and Iskut (in Kitimat-Stikine regional district) reserves. It is noteworthy to mention that these three very low access reserves are randomly scattered across rural BC. In a similar study, Gittelsohn and Sharma [24] measured the driving time to food stores for eight Aboriginal reserves in Western Ontario. They reported that the residents of those reserves drive more than an hour to reach food stores in cities. The Ontario Food and Nutrition Strategy (OFNS) [42] also conducted a qualitative study on the issue of food access among seven reserves in Northern Ontario and 6 reserves in Southern Ontario. The results indicated that neither reserve has healthy food store within their communities. The residents have to drive 45 minutes to Nipigon or 20 minutes to Beardmont to obtain basic foods. They added the even some communities are located over three hours driving distance to the closest grocery stores. By comparing the food access results between $\mathrm{BC}$ and Ontario reserves, in general, residents of $\mathrm{BC}$ reserves have relatively better geographic access to healthy stores.

The results of my study also indicated that residents of reserve and non-reserve communities in rural $\mathrm{BC}$ have equal geographic access (based on driving time) to healthy food stores. On the other hand, Chan et al. [6] reported that $45 \%$ of the on-reserve Aboriginal households in both rural and urban BC suffer from some degree of food insecurity which is more than three times the non-reserves households. As Miewald [43] has shown, geographic food access is one of the components of community food security. McEntee [44] argued that not only is geographic access to food stores important in measuring food security but, also individual access based on income, knowledge, and attitude should be taken into consideration. Some scholars have addressed this issue as social and 
economic inequity which is more pronounced among on-reserves Aboriginal people [45, 46]. To put it simply, residents of rural reserves in $\mathrm{BC}$ might have relatively equal geographic access to healthy food stores compared with non-reserve residents, however, due to constraints in income, education, housing, and transportation they have significantly higher rate of food insecurity. This socioeconomic gap has also been addressed in the Transformative Change Accord which was signed by the Province of British Columbia, the First Nations Leadership Council (FNLC), and the Government of Canada in November 2005 [47]. As a result, residents of low access Aboriginal rural reserves with lower socioeconomic status are highly at potential risk of perpetuate food insecurity.

\section{Conclusion}

In this study, low access rural reserves (estimated in terms of driving time to healthy food stores) are identified in BC. The results indicated that one in four of rural reserves are classified as low access. The results of this study can be highly beneficial to government officials within different jurisdictions and health practitioners to develop or refine food policies toward providing healthy and affordable food to residents of Aboriginal reserves in rural and remote communities. To our knowledge, this study is one of the very few studies in Canada, which evaluated the market food access of rural reserves in terms of driving time to healthy food stores. Future studies are needed to exclusively investigate the traditional food systems and coping strategies of low access residents of Aboriginal reserves in rural BC.

\section{References}

[1] Gates, A., Hanning, R. M., Gates, M., Skinner, K., Martin, I. D., and Tsuji, L. J. 2012. "Vegetable and Fruit Intakes of On-Reserve First Nations Schoolchildren Compared to Canadian Averages and Current Recommendations.” International Journal of Environmental Research and Public Health 9 (4): 1379-97.

[2] Power, E. M. 2008. "Conceptualizing Food Security for Aboriginal People in Canada.” Canadian Journal of
Public Health/Revue Canadienne de sante'e Publique, 95-7.

[3] Skinner, K., Pratley, E., and Burnett, K. 2016. "Eating in the City: A Review of the Literature on Food Insecurity and Indigenous People Living in Urban Spaces.” Societies 6 (2): 7.

[4] Tarasuk, V., Mitchell, A., and Dachner, N. 2013. “Household Food Insecurity in Canada, 2011.” Toronto, (ON): Canadian Institutes of Health Research and Research to Identify Policy Options to Reduce Food Insecurity (PROOF).

[5] Kerstetter, S. A., and Goldberg, M. 2007. “A Review of Policy Options for Increasing Food Security and Income Security in British Columbia: A Discussion Paper.” Provincial Health Services Authority.

[6] Chan, L., Receveur, O., Sharp, D., Schwartz, H., Tikhonov, C., and Mimeault, C. 2011. "First Nation'S Food, Nutrition and Environment Study (Fnfnes): Results from British Columbia (2008/2009)." University of Northern British Columbia.

[7] Fiddler, T. 2012. "Food Security in a Northern First Nations Community: An Exploratory Study on Food Availability and Accessibility." International Journal of Indigenous Health 8 (2): 5.

[8] Gionet, L., and Roshanafshar, S. 2013. "Select Health Indicators of First Nations People Living Off Reserve, Métis and Inuit.” Statistics Canada.

[9] Katzmarzyk, P. T. 2008. "Obesity and Physical Activity among Aboriginal Canadians.” Obesity 16 (1): 184-90.

[10] Lix, L. M., Bruce, S., Sarkar, J., and Young, T. K. 2009. "Risk Factors and Chronic Conditions among Aboriginal and Non-aboriginal Populations." Health Reports 20 (4): 21.

[11] Public Health Agency of Canada. 2011. "Obesity in Canada: Prevalence among Aboriginal Populations.” Available

http://www.phac-aspc.gc.ca/hp-ps/hl-mvs/oic-oac/abo-aut -eng.php.

[12] Foulds, H. J. A., Bredin, S. S. D., and Warburton, D. E. R. 2011. "The Prevalence of Overweight and Obesity in British Columbian Aboriginal adults.” Obesity Reviews 12 (5): e4-11.

[13] Government of Canada. 2011. "Diabetes in Canada: Facts and Figures from a Public Health Perspective.” Available https://www.canada.ca/en/public-health/services/chronicdiseases/reports-publications/diabetes/diabetes-canada-fa cts-figures-a-public-health-perspective/chapter-6.html.

[14] Harris, S. B., Bhattacharyya, O., Dyck, R., Hayward, M. N., and Toth, E. L. 2013. "Type 2 Diabetes in Aboriginal Peoples.” Can J. Diabetes 37 (Suppl 1): S191-6.

[15] Chan, H. M., Fediuk, K., Hamilton, S., Rostas, L., Caughey, A., Kuhnlein, H., and Loring, E. 2006. "Food 
Security in Nunavut, Canada: Barriers and Recommendations." International Journal of Circumpolar Health 65 (5): 416-31.

[16] Reading, C. L., and Wien, F. 2009. "Health Inequalities and the Social Determinants of Aboriginal Peoples' Health.” Prince George, BC: National Collaborating Centre for Aboriginal Health.

[17] The Council of Canadian Academies. 2014. “Aboriginal Food Security in Northern Canada: An Assessment of the State of Knowledge.” Available http://www.scienceadvice.ca/en/assessments/completed/f ood-security.aspx.

[18] Tam, B. Y., Findlay, L., and Kohen, D. 2014. "Social Networks as a Coping Strategy for Food Insecurity and Hunger for Young Aboriginal and Canadian Children.” Societies 4 (3): 463-76.

[19] Carry, C., and Carrington, C. 2011. "Inuit Food Security 2011 Selected Bibliography.”

[20] Fergurson, H. 2011. "Inuit Food (in) Security in Canada: Assessing the Implications and Effectiveness of Policy.” Queen's Policy Review 2 (2): 54-79.

[21] Ford, J. D., and Beaumier, M. 2011. "Feeding the Family during Times of Stress: Experience and Determinants of Food Insecurity in an Inuit Community." The Geographical Journal 177 (1): 44-61.

[22] Campbell, E. A., Shapiro, M. J., Welsh, C., Bleich, S. N., Cobb, L. K., and Gittelsohn, J. 2017.” Healthy Food Availability among Food Sources in Rural Maryland Counties.” Journal of Hunger \& Environmental Nutrition: 1-14.

[23] Larson, N. I., Story, M. T., and Nelson, M. C. 2009. "Neighborhood Environments: Disparities in Access to Healthy Foods in the US." American Journal of Preventive Medicine 36 (1): 74-81.

[24] Gittelsohn, J., and Sharma, S. 2009. "Physical, Consumer, and Social Aspects of Measuring the Food Environment among Diverse Low-Income Populations.” American Journal of Preventive Medicine 36 (4): S161-5.

[25] Willows, N. D. 2005. "Determinants of Healthy Eating in Aboriginal Peoples in Canada." Canadian Journal of Public Health 96 (Supplement 3): S32-36.

[26] Thompson, S., Kamal, A., Alam, M., and Wiebe, J. 2012. "Community Development to Feed the Family in Northern Manitoba Communities: Evaluating Food Activities Based on Their Food Sovereignty, Food Security, and Sustainable Livelihood Outcomes." Canadian Journal of Nonprofit and Social Economy Research 3 (2): 43-66.

[27] Lambden, J., Receveur, O., and Kuhnlein, H. V. 2007. "Traditional Food Attributes Must be Included in Studies of Food Security in the Canadian Arctic.” International Journal of Circumpolar Health 66 (4): 308-19.
[28] Receveur, O., Boulay, M., and Kuhnlein, H. V. 1997. "Decreasing Traditional Food Use Affects Diet Quality for Adult Dene/Metis in 16 Communities of the Canadian Northwest Territories.” The Journal of Nutrition 127 (11): 2179-86.

[29] Sheehy, T., Kolahdooz, F., Schaefer, S. E., Douglas, D. N., Corriveau, A., and Sharma, S. 2015. "Traditional Food Patterns Are Associated with Better Diet Quality and Improved Dietary Adequacy in Aboriginal Peoples in the Northwest Territories, Canada." Journal of human nutrition and dietetics 28 (3): 262-71.

[30] Burgoine, T., and Harrison, F. 2013. "Comparing the Accuracy of Two Secondary Food Environment Data Sources in the UK across Socio-economic and Urban/rural Divides.” International Journal of Health Geographics 12 (1): 2.

[31] Liese, A. D., Colabianchi, N., Lamichhane, A. P., Barnes, T. L., Hibbert, J. D., Porter, D. E., and Lawson, A. B. 2010. "Validation of 3 Food Outlet Databases: Completeness and Geospatial Accuracy in Rural and Urban Food Environments." American Journal of Epidemiology 172 (11): 1324-33.

[32] Lyseen, A. K., and Hansen, H. S. 2014. "Spatial and Semantic Validation of Secondary Food Source Data." ISPRS International Journal of Geo-Information 3 (1): 236-53.

[33] DMTI Enhanced Points of Interest (EPOI) v2015. "[computer file]. Markham, ON: DMTI Spatial Inc., 2015.”

[34] Statistic Canada. 2012. "2012 NAICS definitions: 445110 - Supermarkets and other grocery (except convenience) stores.” Available http://www23.statcan.gc.ca/imdb/p3VD.pl?Function=get VDDetail\&db=imdb\&dis $=2 \& a d m=8 \& T V D=118464 \& C$ $\mathrm{VD}=118471 \& \mathrm{CPV}=445110 \& \mathrm{CST}=01012012 \& \mathrm{MLV}=5$ $\& C L V=5 \& C H V D=$

[35] ESRI. 2014. "ArcGIS Desktop: Release 10.3 Redlands, CA: Environmental Systems Research Institute.”

[36] British Columbia Aboriginal Network on Disability Society. 2015. "BC First Nations.” Available http://www.bcands.bc.ca/british-columbia-aboriginal-com munities/.

[37] Statistics Canada. 2011. "Preview of Census Geography Products and Services. Catalogue no. 92-144-X.” Available http://www.statcan.gc.ca/pub/92-144-x/92-144-x2011001 -eng.pdf.

[38] DMTI Spatial. CanMap ${ }^{\circledR} \quad$ RouteLogistics. 2013. "[machine readable data file]. Markham, ON: DMTI Spatial Inc., 2013.”

[39] Kaufman, P. R. 2010. "Measuring Access to Nutritious, Affordable Food: A National Assessment.” Journal of Food Distribution Research 41 (1): 70-4. 
[40] IBM Corp. 2013. "IBM SPSS Statistics for Windows, Version 22.0. Armonk, NY: IBM Corp.”

[41] Apparicio, P., Cloutier, M. S., and Shearmur, R. 2007. "The Case of Montreal's Missing Food Deserts: Evaluation of Accessibility to Food Supermarkets.” International Journal of Health Geographics 6 (1): 4.

[42] The Ontario Food and Nutrition Strategy. 2014. "First Nations On-Reserve Discussion Report.” Available http://sustainontario.com/wp2011/wp-content/uploads/20 14/03/Report-OFNS-FN-on-reserve-engagment-meetingDec-11-2013.pdf.

[43] Miewald, C. 2014. "Community Food Security and Sustainability." Available http://www.sfu.ca/sustainability/talking/food/2014/comm unity-food-security-and-sustainability.html.
[44] McEntee, J. 2008. "Food Deserts: Contexts and Critiques of Contemporary Food Access Assessments.” BRASS Centre.

[45] Anderson, K. 2016. "A Recognition of Being: Reconstructing Native Womanhood.” Canadian Scholars' Press.

[46] Bell, J., and Standish, M. 2009. "Building Healthy Communities through Equitable Food Access." Community Development Investment Review, 75-87.

[47] Smylie, J. 2013. “Addressing the Social Determinants of Health of Aboriginal Infants, Children and Families in British Columbia.” Available http://www.nccahccnsa.ca/Publications/Lists/Publications /Attachments/89/SDOHforAboriginalChildren_EN_web. pdf. 